\title{
Clinical indications for image-guided interventional procedures in the musculoskeletal system: a Delphi-based consensus paper from the European Society of Musculoskeletal Radiology (ESSR)—part V, knee
}

\author{
Luca Maria Sconfienza ${ }^{1,2} @ \cdot$ Miraude Adriaensen $^{3} \cdot$ Domenico Albano $^{1,4} \cdot$ Andrea Alcala-Galiano $^{5}$. \\ Georgina Allen ${ }^{6,7}$. Maria Pilar Aparisi Gómez ${ }^{8,9}$. Giacomo Aringhieri ${ }^{10} \cdot$ Alberto Bazzocchi $^{11} \cdot$ lan Beggs ${ }^{12}$. \\ Vito Chianca ${ }^{13,14}$. Angelo Corazza ${ }^{1}$. Danoob Dalili ${ }^{15}$. Miriam De Dea ${ }^{16}$. Jose Luis del Cura ${ }^{17}$. Francesco Di Pietto ${ }^{18}$. \\ Elena Drakonaki ${ }^{19}$. Fernando Facal de Castro ${ }^{20}$. Dimitrios Filippiadis ${ }^{21}$ - Salvatore Gitto ${ }^{2}$. Andrew J. Grainger ${ }^{22}$. \\ Simon Greenwood ${ }^{23} \cdot$ Harun Gupta $^{24} \cdot$ Amanda Isaac $^{15,25}$. Slavcho Ivanoski ${ }^{26,27}$. Monica Khanna ${ }^{28}$. \\ Andrea Klauser $^{29} \cdot$ Ramy Mansour $^{30}$. Silvia Martin ${ }^{31}$. Vasco Mascarenhas ${ }^{32,33}$. Giovanni Mauri ${ }^{34,35}$. \\ Catherine McCarthy ${ }^{36}$. David McKean ${ }^{37}$. Eugene McNally ${ }^{36} \cdot$ Kalliopi Melaki $^{38} \cdot$ Rebeca Mirón Mombiela $^{39}$. \\ Ricardo Moutinho ${ }^{32,40}$. Marina Obradov ${ }^{41}$. Cyprian Olchowy ${ }^{42}$. Davide Orlandi43 ${ }^{43}$ Raquel Prada González ${ }^{44}$. \\ Mahesh Prakash ${ }^{45}$. Magdalena Posadzy ${ }^{46}$. Saulius Rutkauskas ${ }^{47}$. Žiga Snoj ${ }^{48,49}$. Alberto Stefano Tagliafico ${ }^{50,51}$. \\ Alexander Talaska ${ }^{52} \cdot$ Xavier Tomas $^{53}$. Violeta Vasilevska-Nikodinovska ${ }^{27,54}$. Jelena Vucetic ${ }^{55}$. David Wilson ${ }^{6}$. \\ Federico Zaottini $^{51} \cdot$ Marcello Zappia $^{56,57} \cdot$ Carmelo Messina $^{1}$
}

Received: 5 March 2021 / Revised: 26 July 2021 / Accepted: 7 August 2021 / Published online: 14 September 2021

(c) The Author(s) 2021, corrected publication 2022

\begin{abstract}
Objectives Interventional procedures around the knee are widely adopted for treating different musculoskeletal conditions. A panel of experts from the Ultrasound and Interventional Subcommittees of the European Society of Musculoskeletal Radiology (ESSR) reviewed the existing literature to assess the evidence on image-guided musculoskeletal interventional procedures around the knee, with the goal of highlighting some controversies associated with these procedures, specifically the role of imaging guidance, as well as the efficacy of the medications routinely injected.

Methods We report the results of a Delphi-based consensus of 53 experts in musculoskeletal radiology, who reviewed the published literature for evidence on image-guided interventional procedures around the knee to derive a list of pertinent clinical indications. Results A list of 10 statements about clinical indications of image-guided procedures around the knee was created by a Delphi-based consensus. Only two of them had the highest level of evidence; all of them received $100 \%$ consensus.

Conclusions Ultrasonography guidance is strongly recommended for intra-articular and patellar tendinopathy procedures to ensure the precision and efficacy of these treatments. Prospective randomized studies remain warranted to better understand the role of imaging guidance and assess some of the medications used for interventional procedures around the knee.

Key Points

- A list of 10 evidence-based statements on clinical indications of image-guided interventional procedures around the knee was produced by an expert panel of the ESSR.

- Strong consensus with $100 \%$ agreement was obtained for all statements.

- Two statements reached the highest level of evidence, allowing us to strongly recommend the use of ultrasonography to guide intra-articular and patellar tendon procedures to ensure higher accuracy and efficacy of these treatments.
\end{abstract}

Keywords Interventional radiology $\cdot$ Knee $\cdot$ Patellar tendon $\cdot$ Platelet-rich plasma $\cdot$ Hyaluronic acid

Luca Maria Sconfienza

io@lucasconfienza.it

Extended author information available on the last page of the article

\section{Abbreviations}

ESSR European Society of Musculoskeletal Radiology

HA Hyaluronic acid

PRP Platelet-rich plasma 
PT Patellar tendinopathy

US Ultrasonography

\section{Introduction}

Interventional procedures around the knee are widely utilized to treat different musculoskeletal conditions. Some of these interventions (e.g., injections or aspirations) are often performed without image guidance, particularly by orthopedists. However, image guidance ensures correct needle position for optimal medication delivery, avoiding injuries to adjacent neurovascular bundles [1-5]. Currently, image guidance for musculoskeletal procedures around the knee has not been incorporated into established guidelines, due to sparse and contentious evidence on its clinical impact in the literature. Moreover, the choice of the procedure is debatable, as new approaches, such as the use of hyaluronic acid (HA) and platelet-rich plasma (PRP), have been recently introduced to treat both joint and tendon conditions [6-8]. Accordingly, the Ultrasound (US) and Interventional Subcommittees of the European Society of Musculoskeletal Radiology (ESSR), together with its Research Committee, initiated in 2019 a collaborative task dedicated to reviewing the existing literature on image-guided musculoskeletal interventional procedures in the lower limb and providing evidence for its clinical indications. This paper reports the list of statements provided by an expert panel of the ESSR and obtained by a Delphi process on published literature evaluating imageguided interventions around the knee.

\section{Materials and methods}

Institutional review board approval was not needed as no patient-specific data were involved. This paper concludes the task carried on by an expert panel of the ESSR which reviewed the evidence of image-guided musculoskeletal interventional procedures in the lower limb. Here, we report the results focusing on tendon, joint, and bursal interventions around the knee. As previously done [9-12], we used a literature-based Delphi process of evidence review including multiple discussion rounds to evaluate the opinion of experts on debatable topics, drafted on the basis of the existing literature, to obtain a final shared agreement [13]. The AGREE II tool was followed to guarantee the quality of this analysis [14]. Supplementary material includes the explanation of the Delphi method steps. The Oxford Centre for Evidencebased Medicine evidence levels were employed to assess the evidence of published papers [15].

\section{Results}

1. Intra-articular US-guided procedures around the knee joint, such as arthrocentesis and intra-articular injections, are more accurate than palpation-guided procedures, resulting in improved fluid aspiration and injection therapeutic outcome(s).

Level of evidence, 1

Agree, $n=53$; disagree, $n=0$; abstain, $n=0$. Agreement $=100 \%$

A systematic review reported that image-guided and particularly US-guided knee injections are more accurate than palpation-guided procedures [16]. A randomized trial also reported superior accuracy of the US-guided technique performed by trainees as compared with palpationguided procedures performed by experienced clinicians [17]. Accuracy rates were high (95-100\%) and similar when injecting the joint through in-plane superolateral, mid-lateral, and mid-medial approaches [18]. Accuracy rates were also high (95\%) using an out-of-plane technique with mid-lateral [19] and mid-medial [20] approachesalthough some authors reported that an out-of-plane mid-medial approach could result in decreased accuracy [19]. Similarly, accuracy rates of US-guided knee arthrocentesis have been reported to be superior to palpation guidance [21]. Most studies reported superior injection benefits [22] and $+183 \%$ improved joint aspiration with improved 2-week outcome [23] using US-guided rather than palpation-guided procedures. Randomized trials comparing US-guided and palpation-guided corticosteroid intra-articular injections $[17,22]$ reported pain reduction at 2-week follow-up, $107 \%$ increase in the responder rate, and $36 \%$ increase in therapeutic duration with subsequent cost reduction, using US guidance [22]. In knee osteoarthritis treated with HA injections, the use of US guidance resulted in enhanced functional and pain-score improvement after 6 and 12 weeks [24], with long-term decreased knee arthroplasty rate [25] when compared to palpation guidance. In emergency settings, both blind and US-guided arthrocentesis were successful, although the latter led to higher volume aspiration for novice practitioners [26].

2. US-guided knee joint injections of corticosteroidanesthetic give short-to-midterm pain relief and functional improvement in inflammatory arthritis. Although similar outcomes may be observed in osteoarthritis, efficacy is controversial, and alternative analgesic therapies (such as oxygen-ozone) have been proposed, but evidence supporting their use remains limited. 
Level of evidence, 2

Agree, $n=53$; disagree, $n=0 ;$ abstain, $n=0$. Agreement $=100 \%$

In a randomized study, US-guided injections of corticosteroid-anesthetic demonstrated pain relief and improved function at 2 and 6 weeks in patients with inflammatory arthritis [17]. In knee osteoarthritis, US-guided intra-articular administration of corticosteroid-anesthetic has been shown to produce similar clinical and functional outcomes at 1,2 , and 4 weeks in a randomized study compared to oxygen-ozone injection [27], as well as in a cohort study [28]. However, no outcome difference was found in another randomized trial comparing US-guided injections of placebo or corticosteroid at 2-week follow-up [29]. These findings are consistent with a systematic review and meta-analysis including both US-guided and palpation-guided injections, where no clear clinical advantage of corticosteroids use was found in the short-to-midterm [30]. Furthermore, repeated corticosteroid use has been reported to accelerate cartilage volume loss in a 2-year clinical trial that randomized patients with knee osteoarthritis to triamcinolone or placebo injections [31]. Hence, current evidence supports the use of USguided injections of corticosteroid-anesthetic in inflammatory arthritis, but it is contradictory about their efficacy and cautious about the long-term safety of repeated injections in knee osteoarthritis.

Regarding other US-guided intra-articular analgesic treatments, a randomized controlled study compared oxygen-ozone efficacy with that of corticosteroid at 1 week, 1 month, and 3 months [27]. Both therapies were effective in improving symptoms and functional outcomes at 1 week and 1 month. This improvement was sustained for 3 months in patients treated with oxygen-ozone but not with corticosteroids [27].

\section{US-guided HA intra-articular injections are safe and} improve pain scores and function in knee osteoarthritis, showing greater efficacy than steroids in the long term.

Level of evidence, 3

Agree, $n=53$; disagree, $n=0$; abstain, $n=0$. Agreement $=100 \%$

Systematic reviews of overlapping meta-analyses found that HA injections are effective in treating knee osteoarthritis with no increased risk of adverse events [32], with positive effects lasting up to 26 weeks [33]. Most studies used blind techniques to perform injections. Nevertheless, a case-control retrospective study reported that US-guided HA injection improved pain and function at 6-month followup [34]. Greater pain reduction was observed compared to intra-articular corticosteroid injections [34]. These findings are concordant with a previous meta-analysis including high-quality randomized trials using intra-articular corticosteroid and HA injections, regardless of the injection approach [35]. Efficacy on pain was greater in the corticosteroid group in the short term (up to 1 month), similar in midterm (3 months), and greater in the HA group in the long term (6 months) [35]. US guidance improved injection accuracy and clinical outcomes at 6- and 12-week follow-up compared with palpation-guided injections in a randomized trial [24]. Long-term, precise intra-articular injection of HA by US guidance was associated with a reduced knee arthroplasty rate compared to the palpation-guided approach, particularly in obese patients [25, 32].

4. US-guided injections of regenerative medications have been reported to show clinical benefit by relieving pain and enhancing function in patients with knee osteoarthritis but lack randomized controlled trial evidence.

Level of evidence, 3

Agree, $n=53$; disagree, $n=0 ;$ abstain, $n=0$. Agreement $=100 \%$

Regenerative therapies have emerged as alternative strategies to treat knee osteoarthritis. Among them, blood derivatives such as PRP [36], autologous conditioned serum [37], and autologous protein solution [38] intra-articular administration under US guidance safely produced clinical improvement observed early after treatment and sustained up to 1 year thereafter [36-38]. Adding growth hormone to PRP improved joint function in the short term [39]. However, the efficacy of blood derivatives remains controversial. A randomized controlled trial reported similar improvements up to 6 months after saline injection [38]. Larger randomized controlled studies providing longer-term follow-up are needed.

US-guided injections of other regenerative substances, such as adipose-derived stem cells [40] and amniotic membrane/umbilical cord particulate [41], have shown clinical and functional improvements up to 6 and 12 months after treatment in non-controlled studies on small series. Evidence regarding their clinical use remains limited. Prolotherapy has been reported to be less effective than PRP in reducing pain and functional limitation in patients with knee osteoarthritis [36].

5. US-guided procedures around the menisci are promising for short-term pain management, but evidence supporting their use is limited.

Level of evidence, 4

Agree, $n=53$; disagree, $n=0 ;$ abstain, $n=0$. Agreement $=100 \%$

In patients with knee osteoarthritis and meniscal extrusion [42], tear, or degeneration [43], US-guided 
meniscus-targeted corticosteroid injections have been reported to relieve pain at short-term follow-up (at 1-4 weeks [42] and 5-6 weeks on average [43]). The absence of a control group is the main limitation of these studies. However, these preliminary findings encourage future higher-quality research. US-guided drainage of meniscal cysts with subsequent corticosteroid and anesthetic injection has been proposed as a safe and well-tolerated option to delay surgery, with complete symptom resolution reported at an average follow-up of 10 months in more than half of patients [44]. Higher-quality studies with longer-term follow-up are absent.

6. In fat pad-related anterior knee pain syndromes, USguided corticosteroid-anesthetic injection and fat pad alcohol ablation might be safe and effective in shortterm pain reduction, although no randomized studies are available.

Level of evidence, 4

Agree, $n=53$; disagree, $n=0$; abstain, $n=0$. Agreement $=100 \%$

Anterior knee pain may be associated with inflammation, hypertrophy, or edema of fat pads resulting in impingement syndromes [45, 46]. US-guided corticosteroid-anesthetic injections are safe and effective in the short-term reduction of pain secondary to suprapatellar fad pad inflammation [45]. A non-randomized study compared physical therapy with and without prior US-guided corticosteroid-anesthetic injection for suprapatellar fat-pad edema, showing a greater pain reduction in the injected patients at 1-month follow-up but not at 6-month follow-up [45]. Furthermore, an uncontrolled study on 12 patients with infrapatellar fat pad impingement syndrome evaluated the efficacy of serial US-guided ethanol-bupivacaine injections, resulting in pain reduction at 6-week follow-up [46]. However, the evidence is still limited.

7. US-guided dry needling is effective in improving function and pain in patellar tendinopathy (PT), especially if associated with PRP. Conflicting results about the clinical effectiveness of PRP in PT do not allow supporting the use of this treatment as a firstline approach.

Level of evidence, 1

Agree, $n=53$; disagree, $n=0 ;$ abstain, $n=0$. Agreement $=100 \%$

A meta-analysis on nonsurgical approaches for PT confirmed that dry needling was one of the non-invasive treatments demonstrating clinical improvement [47]. Retrospective and case studies showed clinical improvement at 4 weeks in around 74\% of cases [48-51]. Housner reported excellent to good satisfaction scoring at 4 weeks in $81 \%$ of 47 patients with recalcitrant PT with, however, one tendon rupture [49]. Pain improvement for refractory PT was reported combining two dry needlings with autologous blood injections performed 4 weeks apart [52]. US-guided PRP injection combined with dry needling and eccentric loading exercise was shown to be more effective than dry needling alone in refractory PT at 12 weeks [53]. Furthermore, dry needling was more effective than eccentric loading exercises alone [53]. PRP injection was more effective than extracorporeal shockwave therapy at 6 and 12 months follow-up [54]. High-volume and PRP injections were reported as having similar efficacy in the short term, while positive effects of high-volume injections gradually diminished and PRP showed greater efficacy in the medium term. However, their combination provided better results at 6 months [55]. Conversely, one study showed PRP alone had a similar clinical effect at 12 weeks when compared to saline [56].

8. Other US-guided treatments have been shown to be safe for treating PT (corticosteroid, high-volume injections, prolotherapy, sclerosing injections with polidocanol, and HA). However, no studies compared them; thus clinical superiority of one treatment over another still needs clarification.

Level of evidence, 3

Agree, $n=53$; disagree, $n=0 ;$ abstain, $n=0$. Agreement $=100 \%$

Peritendinous corticosteroid injection for PT has been shown to be more effective than placebo at 3 months. However, it caused reversible short-term skin atrophy in $37 \%$ [57]. Further, some patients presented symptoms of relapse within 6 months when combined with aggressive rehabilitation.

US-guided high-volume injection has shown good shortterm results in athletes and nonathletes $[58,59]$. US-guided high-volume corticosteroid-anesthetic and saline injection have shown good results in PT [58, 59]. One study recommended post-injection physical therapy using eccentric loading [59]. Conversely, ambiguous results have been reported using high-volume image-guided injection for PT, with all patients showing clinical improvement, but $6 / 28$ patients required surgery after treatment and 2/28 had additional corticosteroid injection [60].

Hyperosmolar dextrose prolotherapy can be safely used to treat intractable Osgood-Schlatter's disease and chronic PT in young adolescents and adults. Some evidence suggests greater symptom improvement after prolotherapy than the usual conservative treatment $[61,62]$. However, a randomized controlled trial on 49 knees with Osgood-Schlatter's disease failed to show any pain difference after prolotherapy compared to lidocaine injection alone [63]. 
Small-cohort randomized controlled studies on sclerosing injections on groups of athletes and nonathletes reported improvement in knee function with short-term pain reduction [64, 65]. Moreover, this technique seems to offer longterm pain relief $[66,67]$.

US-guided HA injection is a safe and feasible treatment for PT pain [68]. US-guided peritendinous injections of HA performed on three occasions 1 week apart were safe, showing pain relief, a decrease in tendon thickness, and decreasing neovascularization at 3 weeks [69]. In a small series, 3 weeks of HA peritendinous injections showed a reduction in swelling and tenderness without adverse events [70].

9. US-guided aspiration, wall fenestration, and corticosteroid injection of Baker's cysts are safe and effective procedures in relieving pain and reducing cyst volume in patients with Baker's cysts secondary to internal knee derangement.

Level of evidence, 3

Agree, $n=53$; disagree, $n=0$; abstain, $n=0$. Agreement $=100 \%$

Although Baker's cyst therapy depends on the primary cause, percutaneous interventions can be safely performed under US guidance [71-73]. In patients with knee osteoarthritis, US-guided Baker's cyst aspiration and corticosteroidanesthetic injection have shown significant pain relief and cyst diameters decrease up to $4[71,72]$ and 8 weeks [73]. Direct Baker's cyst injection gave a greater size reduction and better clinical outcomes compared to an anterior knee joint injection at 4- and 8-week follow-up [73]. Aspiration and corticosteroid injection performed better than standalone physical therapy, even though their combination further ameliorated symptoms [72]. At long-term follow-up in patients with knee osteoarthritis [74] or other knee pathologies [75], US-guided aspiration, wall fenestration in the case of multilocular cysts, and injection of anesthetic and corticosteroid showed similar clinical benefit by relieving pain $[74,75]$ and reducing cyst volume [74]. A significant correlation exists between volume reduction and clinical improvement [74]. Baker's cyst recurrence was noted in complex cysts, without any significant pain change between the patients with simple and complex cysts [74]. Close followup may be advantageous so the treatment can be repeated in case of recurrence [74]. In two case reports, US-guided sclerotherapy with hypertonic dextrose has been used as a treatment option for Baker's cyst treatment [76, 77], but the clinical value has not still been demonstrated. US-guided intervention in Baker's cyst when visually observed by the patient can be used as a positive bio-feedback, favorably affecting the treatment outcome [78].
10. US-guided corticosteroid injections are more effective than blind injections to treat pes anserinus bursitis, but the added value of imaging to guide other periarticular injections (excluding patellar tendon and Baker's cyst) has not been demonstrated.

Level of evidence, 3

Agree, $n=53$; disagree, $n=0$; abstain, $n=0$. Agreement $=100 \%$

A prospective randomized cadaveric study has shown that US-guided injections in the pes anserinus bursa are feasible and more accurate than palpation-guided injections [79]. A prospective controlled study comparing US-guided to blind corticosteroid injections into the pes anserinus bursa of patients with bursitis showed that the US-guided injections resulted in greater improvement at 1 and 4 weeks compared to blind injections [80]. Based on review papers, possible interventions in the prepatellar bursa include US-guided corticosteroid injection into an inflamed bursa or aspiration for diagnosis of infection or other synovial pathology [81]. However, no information about efficacy is available. Smith et al. showed $83-100 \%$ accuracy of needle placement into the popliteus tendon sheath. Finnoff et al. achieved 92\% accuracy in injecting the pes anserinus bursa with US guidance but only $17 \%$ accuracy using landmark injections [79]. Jose et al. injected corticosteroid and anesthetic into the medial collateral ligament bursa [82], while Hong et al. used the same mixture for iliotibial band syndrome [83]. More studies comparing guidance modalities and corticosteroids to other therapies are needed.

\section{Discussion}

We found some evidence concerning image-guided procedures around the knee. In all statements, US guidance has been established as pivotal, as accuracy and clinical outcome are generally higher compared to palpation-guided procedures with the highest level of evidence (statement \#1). Moreover, US-guided injection of corticosteroid-anesthetic has proven to be effective in the short-to-midterm follow-up for treating inflammatory arthritis with a level of evidence 2 (statement \#2). Conversely, despite being seemingly safe and effective in treating osteoarthritis, strong evidence is still lacking for US-guided injections of HA (statement \#3) and regenerative medications (statement \#4). Furthermore, only small case series are available for US-guided procedures around the menisci and injections and alcohol ablation in knee anterior fat pad-related syndromes, reporting promising results that require to be further confirmed by larger series.

Regarding periarticular treatments, $\mathrm{PT}$ is the most investigated topic. According to our results, US-guided dry 
needling is highly effective in PT with a higher level of evidence (statement \#7). Notably, although the association of PRP to dry needling seems to improve the outcome, there are still conflicting results concerning the value of PRP alone for PT, leading us to recommend avoiding this treatment as a first-line strategy. Although different safe and effective US-guided treatment options exist, no randomized prospective studies have effectively clarified which one should be preferred as the best choice (statement \#8). Last, US-guided treatments of Baker's cyst (statement \#9) and pes anserinus bursitis (statement \#10) are both safe and effective, but the level of evidence of these procedures is still too low to strongly recommend these treatments.

In summary, ten statements regarding US-guided musculoskeletal interventions around the knee have been provided by a working group of experts from the ESSR. US guidance is strongly recommended for intra-articular and PT procedures to ensure higher accuracy and efficacy. Prospective randomized studies remain warranted, especially for knee procedures with low levels of evidence.

Supplementary Information The online version contains supplementary material available at https://doi.org/10.1007/s00330-021-08258-1.

Acknowledgements All of the authors are members of the Ultrasound and/or Interventional Subcommittees of the European Society of Musculoskeletal Radiology (ESSR).

Funding Open access funding provided by Università degli Studi di Milano within the CRUI-CARE Agreement. The authors state that this work has not received any funding.

\section{Declarations}

Guarantor The scientific guarantor of this publication is Luca Maria Sconfienza, MD PhD.

Conflict of Interest The authors of this manuscript declare no relationships with any companies whose products or services may be related to the subject matter of the article.

Statistics and Biometry No complex statistical methods were necessary for this paper.

Informed Consent No informed consent was needed as this paper does not involve patients.

Ethical Approval Institutional Review Board approval was not required because this paper does not involve patients.

\section{Methodology}

Literature-based Delphi process

Open Access This article is licensed under a Creative Commons Attribution 4.0 International License, which permits use, sharing, adaptation, distribution and reproduction in any medium or format, as long as you give appropriate credit to the original author(s) and the source, provide a link to the Creative Commons licence, and indicate if changes were made. The images or other third party material in this article are included in the article's Creative Commons licence, unless indicated otherwise in a credit line to the material. If material is not included in the article's Creative Commons licence and your intended use is not permitted by statutory regulation or exceeds the permitted use, you will need to obtain permission directly from the copyright holder. To view a copy of this licence, visit http://creativecommons.org/licenses/by/4.0/.

\section{References}

1. Silvestri E, Barile A, Albano D et al (2018) Interventional therapeutic procedures in the musculoskeletal system: an Italian Survey by the Italian College of Musculoskeletal Radiology. Radiol Medica 123:314-321

2. Albano D, Chianca V, Tormenta S et al (2017) Old and new evidence concerning the crucial role of ultrasound in guiding intraarticular injections. Skeletal Radiol 46:963-964. https://doi.org/ 10.1007/s00256-017-2644-3

3. Chan BY, Lee KS (2018) Ultrasound intervention of the lower extremity/pelvis. Radiol Clin North Am 56:1035-1046. https:// doi.org/10.1016/j.rcl.2018.06.011

4. Sheth T, Miranda OM, Johnson B (2021) Assessment of patient satisfaction, functionality, and quality of life after ultrasoundguided knee intervention: a prospective study. Clin Rheumatol 40:735-740. https://doi.org/10.1007/s10067-020-05254-6

5. Sconfienza LM, Albano D, Messina C et al (2020) Ultrasoundguided percutaneous tenotomy of the long head of biceps tendon in patients with symptomatic complete rotator cuff tear: in vivo non-controlled prospective study. J Clin Med 9:2114. https:// doi.org/10.3390/jcm 9072114

6. Albano D, Messina C, Usuelli FG et al (2017) Magnetic resonance and ultrasound in Achilles tendinopathy: predictive role and response assessment to platelet-rich plasma and adipose-derived stromal vascular fraction injection. Eur J Radiol 95:130-135. https://doi.org/10.1016/j.ejrad.2017.08.006

7. Strauss EJ, Hart JA, Miller MD et al (2009) Hyaluronic acid viscosupplementation and osteoarthritis: current uses and future directions. Am J Sports Med 37:1636-1644. https://doi.org/10. 1177/0363546508326984

8. Ren H, Zhang S, Wang X, et al (2020) Role of platelet-rich plasma in the treatment of osteoarthritis: a meta-analysis. J Int Med Res. https://doi.org/10.1177/0300060520964661

9. Sconfienza LM, Albano D, Allen G et al (2018) Clinical indications for musculoskeletal ultrasound updated in 2017 by European Society of Musculoskeletal Radiology (ESSR) consensus. Eur Radiol 28:5338-5351. https://doi.org/10.1007/ s00330-018-5474-3

10. Sconfienza LM, Adriaensen M, Albano D, et al (2020) Clinical indications for image-guided interventional procedures in the musculoskeletal system: a Delphi-based consensus paper from the European Society of Musculoskeletal Radiology (ESSR) - part I, shoulder. Eur Radiol. https://doi.org/10.1007/s00330-019-06419-x

11. Sconfienza LM, Adriaensen M, Albano D et al (2020) Clinical indications for image-guided interventional procedures in the musculoskeletal system: a Delphi-based consensus paper from the European Society of Musculoskeletal Radiology (ESSR)—part II, elbow and wrist. Eur Radiol 30:2220-2230

12. Sconfienza LM, Adriaensen M, Albano D et al (2020) Clinical indications for image guided interventional procedures in the musculoskeletal system: a Delphi-based consensus paper from the European Society of Musculoskeletal Radiology (ESSR) - part III, nerves of the upper limb. Eur Radiol 30:1498-1506. https:// doi.org/10.1007/s00330-019-06479-z 
13. Steurer J (2011) The Delphi method: an efficient procedure to generate knowledge. Skeletal Radiol 40:959-961. https://doi.org/ 10.1007/s00256-011-1145-Z

14. Messina C, Vitale JA, Pedone L et al (2020) Critical appraisal of papers reporting recommendation on sarcopenia using the AGREE II tool: a EuroAIM initiative. Eur J Clin Nutr 74:11641172. https://doi.org/10.1038/s41430-020-0638-z

15. Oxford Centre for Evidence based Medicine (2011) The Oxford 2011 levels of evidence. Group 1:5653.

16. Maricar N, Parkes MJ, Callaghan MJ et al (2013) Where and how to inject the knee-a systematic review. Semin Arthritis Rheum 43:195-203. https://doi.org/10.1016/j.semarthrit.2013.04.010

17. Cunnington J, Marshall N, Hide G, et al (2010) A randomised, controlled, double blinded study of ultrasound guided corticosteroid joint injection in patients with inflammatory arthritis. Arthritis Rheum 62:1862-1869. https://doi.org/10.1002/art.27448

18. Park KD, Ahn JK, Lee S-C et al (2013) Comparison of ultrasoundguided intra-articular injections by long axis in plane approach on three different sites of the knee. Am J Phys Med Rehabil 92:990 998. https://doi.org/10.1097/PHM.0b013e3182923691

19. Park Y, Lee SC, Nam H-S et al (2011) Comparison of sonographically guided intra-articular injections at 3 different sites of the knee. J Ultrasound Med 30:1669-1676. https://doi.org/10.7863/ jum.2011.30.12.1669

20. Jang SH, Lee SC, Lee JH et al (2013) Comparison of ultrasound (US)-guided intra-articular injections by in-plain and out-ofplain on medial portal of the knee. Rheumatol Int 33:1951-1959. https://doi.org/10.1007/s00296-012-2660-5

21 Wu T, Dong Y, Song Hx et al (2016) Ultrasound-guided versus landmark in knee arthrocentesis: a systematic review. Semin Arthritis Rheum 45:627-632. https://doi.org/10.1016/j.semarthrit. 2015.10.011

22. Sibbitt WL, Band PA, Kettwich LG et al (2011) A randomized controlled trial evaluating the cost-effectiveness of sonographic guidance for intra-articular injection of the osteoarthritic knee. J Clin Rheumatol 17:409-415. https://doi.org/10.1097/RHU.0b013 e31823a49a4

23. Sibbitt W, Kettwich L, Band P et al (2012) Does ultrasound guidance improve the outcomes of arthrocentesis and corticosteroid injection of the knee? Scand J Rheumatol 41:66-72. https://doi. org/10.3109/03009742.2011.599071

24. Kianmehr N, Hasanzadeh A, Naderi F et al (2018) A randomized blinded comparative study of clinical response to surface anatomy guided injection versus sonography guided injection of hyaloronic acid in patients with primary knee osteoarthritis. Int J Rheum Dis 21:134-139. https://doi.org/10.1111/1756-185X.13123

25. Lundstrom ZT, Sytsma TT, Greenlund LS (2020) Rethinking viscosupplementation: ultrasound- versus landmark-guided injection for knee osteoarthritis. J Ultrasound Med 39:113-117. https://doi. org/10.1002/jum. 15081

26. Wiler JL, Costantino TG, Filippone L, Satz W (2010) Comparison of ultrasound-guided and standard landmark techniques for knee arthrocentesis. J Emerg Med 39:76-82. https://doi.org/10.1016/j. jemermed.2008.05.012

27. Babaei-Ghazani A, Najarzadeh S, Mansoori K et al (2018) The effects of ultrasound-guided corticosteroid injection compared to oxygen-ozone $(\mathrm{O} 2-\mathrm{O} 3)$ injection in patients with knee osteoarthritis: a randomized controlled trial. Clin Rheumatol 37:25172527. https://doi.org/10.1007/s10067-018-4147-6

28. Jørgensen TS, Graven-Nielsen T, Ellegaard K et al (2014) Intraarticular analgesia and steroid reduce pain sensitivity in knee OA patients: an interventional cohort study. Pain Res Treat 2014:1-6. https://doi.org/10.1155/2014/710490

29. Henriksen M, Christensen R, Klokker L et al (2015) Evaluation of the benefit of corticosteroid injection before exercise therapy in patients with osteoarthritis of the knee. JAMA Intern Med 175:923. https://doi.org/10.1001/jamainternmed.2015.0461

30. Jüni P, Hari R, Rutjes AW, et al (2015) Intra-articular corticosteroid for knee osteoarthritis. Cochrane Database Syst Rev 2-3. https://doi.org/10.1002/14651858.CD005328.pub3

31. McAlindon TE, LaValley MP, Harvey WF et al (2017) Effect of intra-articular triamcinolone vs saline on knee cartilage volume and pain in patients with knee osteoarthritis. JAMA 317:1967. https://doi.org/10.1001/jama.2017.5283

32. Xing D, Wang B, Liu Q et al (2016) Intra-articular hyaluronic acid in treating knee osteoarthritis: a PRISMA-compliant systematic review of overlapping meta-analysis. Sci Rep 6:32790. https://doi. org/10.1038/srep32790

33. Campbell KA, Erickson BJ, Saltzman BM et al (2015) Is local viscosupplementation injection clinically superior to other therapies in the treatment of osteoarthritis of the knee: a systematic review of overlapping meta-analyses. Arthroscopy 31:2036-2045. e14. https://doi.org/10.1016/j.arthro.2015.03.030

34. Parisi S, Ditto MC, Priora M, et al (2020) Ultrasound-guided intra-articular injection: efficacy of hyaluronic acid compared to glucocorticoid in the treatment of knee osteoarthritis. Minerva Med. https://doi.org/10.23736/S0026-4806.19.06190-1

35. He W, Kuang M, Zhao J et al (2017) Efficacy and safety of intraarticular hyaluronic acid and corticosteroid for knee osteoarthritis: a meta-analysis. Int J Surg 39:95-103. https://doi.org/ 10.1016/j.ijsu.2017.01.087

36. Rahimzadeh P, Imani F, Faiz SHR et al (2018) The effects of injecting intra-articular platelet-rich plasma or prolotherapy on pain score and function in knee osteoarthritis. Clin Interv Aging 13:73-79. https://doi.org/10.2147/CIA.S147757

37. Barreto A, Braun TR (2017) A new treatment for knee osteoarthritis: clinical evidence for the efficacy of Arthrokinex ${ }^{\mathrm{TM}}$ autologous conditioned serum. J Orthop 14:4-9. https://doi.org/ 10.1016/j.jor.2016.10.008

38. Kon E, Engebretsen L, Verdonk P et al (2018) Clinical outcomes of knee osteoarthritis treated with an autologous protein solution injection: a 1-year pilot double-blinded randomized controlled trial. Am J Sports Med 46:171-180. https://doi.org/ $10.1177 / 0363546517732734$

39. Rahimzadeh P, Imani F, Faiz S-H-R, et al (2016) Adding intraarticular growth hormone to platelet rich plasma under ultrasound guidance in knee osteoarthritis: a comparative doubleblind clinical trial. Anesthesiol Pain Med. https://doi.org/10. 5812/aapm.41719

40. Panchal J, Malanga G, Sheinkop M (2018) Safety and efficacy of percutaneous injection of Lipogems micro-fractured adipose tissue for osteoarthritic knees. Am J Orthop (Belle Mead NJ) 47:1-11. https://doi.org/10.12788/ajo.2018.0098

41. Castellanos R, Tighe S (2019) Injectable amniotic membrane/ umbilical cord particulate for knee osteoarthritis: a prospective, single-center pilot study. Pain Med 20:2283-2291. https://doi. org/10.1093/pm/pnz143

42. Di Sante L, Venditto T, Ioppolo F et al (2019) Ultrasound guided injection of a painful knee osteoarthritis with medial meniscus extrusion: a case series study. Muscle Ligaments Tendons J 07:331. https://doi.org/10.32098/mltj.02.2017.16

43. Wilderman I, Berkovich R, Meaney C et al (2019) Meniscustargeted injections for chronic knee pain due to meniscal tears or degenerative fraying: a retrospective study. J Ultrasound Med 38:2853-2859. https://doi.org/10.1002/jum.14987

44. MacMahon PJ, Brennan DD, Duke D et al (2007) Ultrasoundguided percutaneous drainage of meniscal cysts: preliminary clinical experience. Clin Radiol 62:683-687. https://doi.org/10. 1016/j.crad.2007.02.007

45. Ozdemir ZM, Aydingoz U, Korkmaz MF, et al (2016) Ultrasonography-guided injection for quadriceps fat pad edema: 
preliminary report of a six-month clinical and radiological follow-up. J Belgian Soc Radiol. https://doi.org/10.5334/jbr-btr. 1148

46. House CV, Connell DA (2007) Therapeutic ablation of the infrapatellar fat pad under ultrasound guidance: a pilot study. Clin Radiol 62:1198-1201. https://doi.org/10.1016/j.crad.2007.07. 005

47. Chen PC, Wu KT, Chou WY et al (2019) Comparative effectiveness of different nonsurgical treatments for patellar tendinopathy: a systematic review and network meta-analysis. Arthrosc - J Arthrosc Relat Surg 35:3117-3131.e2. https://doi.org/10.1016/j. arthro.2019.06.017

48. Kanaan Y, Jacobson JA, Jamadar D et al (2013) Sonographically guided patellar tendon fenestration: prognostic value of preprocedure sonographic findings. J Ultrasound Med 32:771-777. https:// doi.org/10.7863/ultra.32.5.771

49. Housner JA, Jacobson JA, Morag Y et al (2010) Should ultrasound-guided needle fenestration be considered as a treatment option for recalcitrant patellar tendinopathy? A retrospective study of 47 cases. Clin J Sport Med 20:488-490. https://doi.org/ 10.1097/JSM.0b013e3181f3617f

50. Testa V, Capasso G, Maffulli N, Bifulco G (1999) Ultrasoundguided percutaneous longitudinal tenotomy for the management of patellar tendinopathy. Med Sci Sports Exerc 31:1509-1515. https://doi.org/10.1097/00005768-199911000-00003

51. Housner JA, Jacobson JA, Misko R (2009) Sonographically guided percutaneous needle tenotomy for the treatment of chronic tendinosis. J Ultrasound Med 28:1187-1192. https:// doi.org/10.7863/jum.2009.28.9.1187

52. James SLJ, Ali K, Pocock C et al (2007) Ultrasound guided dry needling and autologous blood injection for patellar tendinosis. Br J Sports Med 41:518-521. https://doi.org/10.1136/bjsm. 2006.034686

53. Dragoo JL, Wasterlain AS, Braun HJ, Nead KT (2014) Plateletrich plasma as a treatment for patellar tendinopathy: a doubleblind, randomized controlled trial. Am J Sports Med 42:610 618. https://doi.org/10.1177/0363546513518416

54. Vetrano M, Castorina A, Vulpiani MC et al (2013) Platelet-rich plasma versus focused shock waves in the treatment of Jumper's knee in athletes. Am J Sports Med 41:795-803. https://doi.org/ 10.1177/0363546513475345

55. Abate M, Di Carlo L, Verna S et al (2018) Synergistic activity of platelet rich plasma and high volume image guided injection for patellar tendinopathy. Knee Surgery, Sport Traumatol Arthrosc 26:3645-3651. https://doi.org/10.1007/s00167-018-4930-6

56. Scott A, LaPrade RF, Harmon KG et al (2019) Platelet-rich plasma for patellar tendinopathy: a randomized controlled trial of leukocyte-rich PRP or leukocyte-poor PRP versus saline. Am J Sports Med 47:1654-1661. https://doi.org/10.1177/03635 46519837954

57. Fredberg U, Bolvig L, Pfeiffer-Jensen M et al (2004) Ultrasonography as a tool for diagnosis, guidance of local steroid injection and together with pressure algometry, monitoring of the treatment of athletes with chronic jumper's knee and Achilles tendinitis: a randomized, double-blind, placebo-controlled study. Scand J Rheumatol 33:94-101. https://doi.org/10.1080/ 03009740310004126

58. Maffulli N, Del Buono A, Oliva F et al (2016) High-volume image-guided injection for recalcitrant patellar tendinopathy in athletes. Clin J Sport Med 26:12-16. https://doi.org/10.1097/ JSM.0000000000000242

59. Morton S, Chan O, King J et al (2014) High volume imageguided Injections for patellar tendinopathy: a combined retrospective and prospective case series. Muscles Ligaments
Tendons J 4:214-219. https://doi.org/10.11138/mltj/2014.4.2. 214

60. Nielsen TG, Miller LL, Mygind-Klavsen B, Lind M (2020) High-volume image-guided injection in the chronic recalcitrant non-insertional patellar tendinopathy: a retrospective case series. J Exp Orthop. https://doi.org/10.1186/ s40634-020-00299-7

61. Ryan M, Wong A, Rabago D et al (2011) Ultrasound-guided injections of hyperosmolar dextrose for overuse patellar tendinopathy: a pilot study. Br J Sports Med 45:972-977. https://doi.org/10. 1136/bjsm.2010.081455

62. Topol GA, Podesta LA, Reeves KD, et al (2011) Hyperosmolar dextrose injection for recalcitrant Osgood-Schlatter disease. Pediatrics. doi: https://doi.org/10.1542/peds.2010-1931

63. Nakase J, Oshima T, Takata Y et al (2020) No superiority of dextrose injections over placebo injections for Osgood-Schlatter disease: a prospective randomized double-blind study. Arch Orthop Trauma Surg 140:197-202. https://doi.org/10.1007/ s00402-019-03297-2

64. Hoksrud A, Öhberg L, Alfredson H, Bahr R (2006) Ultrasoundguided sclerosis of neovessels in painful chronic patellar tendinopathy: a randomized controlled trial. Am J Sports Med 34:17381746. https://doi.org/10.1177/0363546506289168

65. Willberg L, Sunding K, Forssblad M et al (2011) Sclerosing polidocanol injections or arthroscopic shaving to treat patellar tendinopathy/jumper's knee? A randomised controlled study. $\mathrm{Br}$ J Sports Med 45:411-415. https://doi.org/10.1136/bjsm.2010. 082446

66. Hoksrud A, Bahr R (2011) Ultrasound-guided sclerosing treatment in patients with patellar tendinopathy (Jumper's knee): 44-month follow-up. Am J Sports Med 39:2377-2380. https:// doi.org/10.1177/0363546511417097

67. Hoksrud A, Torgalsen T, Harstad H et al (2012) Ultrasoundguided sclerosis of neovessels in patellar tendinopathy: a prospective study of 101 patients. Am J Sports Med 40:542-547. https:// doi.org/10.1177/0363546511433012

68. Kumai T, Muneta T, Tsuchiya A et al (2014) The short-term effect after a single injection of high-molecular-weight hyaluronic acid in patients with enthesopathies (lateral epicondylitis, patellar tendinopathy, insertional Achilles tendinopathy, and plantar fasciitis): a preliminary study. J Orthop Sci 19:603-611. https://doi.org/10. 1007/s00776-014-0579-2

69. Fogli M, Giordan N, Mazzoni G (2017) Efficacy and safety of hyaluronic acid (500-730kDa) ultrasound-guided injections on painful tendinopathies: a prospective, open label, clinical study. Muscles Ligaments Tendons J 7:388-395. https://doi.org/10. $11138 / \mathrm{mltj} / 2017.7 .2 .388$

70. Frizziero A, Oliva F, Vittadini F et al (2019) Efficacy of ultrasound-guided hyaluronic acid injections in Achilles and patellar tendinopathies: a prospective multicentric clinical trial. Muscles Ligaments Tendons J 9:305-313. https://doi.org/10.32098/mltj. 03.2019 .01

71. Di Sante L, Paoloni M, Ioppolo F et al (2010) Ultrasound-guided aspiration and corticosteroid injection of Baker's cysts in knee osteoarthritis. Am J Phys Med Rehabil 89:970-975. https://doi. org/10.1097/PHM.0b013e3181fc7da2

72. Di Sante L, Paoloni M, Dimaggio M et al (2012) Ultrasoundguided aspiration and corticosteroid injection compared to horizontal therapy for treatment of knee osteoarthritis complicated with Baker's cyst: a randomized, controlled trial. Eur J Phys Rehabil Med 48:561-567

73. Bandinelli F, Fedi R, Generini S et al (2012) Longitudinal ultrasound and clinical follow-up of Baker's cysts injection with 
steroids in knee osteoarthritis. Clin Rheumatol 31:727-731. https://doi.org/10.1007/s10067-011-1909-9

74. Köroğlu M, Çallıŏglu M, Eriş HN et al (2012) Ultrasound guided percutaneous treatment and follow-up of Baker's cyst in knee osteoarthritis. Eur J Radiol 81:3466-3471. https://doi.org/10.1016/j. ejrad.2012.05.015

75. Smith MK, Lesniak B, Baraga MG, Kaplan L, Jose J (2015) Treatment of popliteal (Baker) cysts with ultrasound-guided aspiration, fenestration, and injection. Sports Health 7:409-414. https://doi. org/10.1177/1941738115585520

76 Yavuz F, Kibar S, Balaban B (2016) Hypertonic dextrose injection for the treatment of a Baker's cyst. J Clin Diagnostic Res 10:YD01-YD02. https://doi.org/10.7860/JCDR/2016/17919.7290

77. Centeno CJ, Schultz J, Freeman M (2008) Sclerotherapy of Baker's cyst with imaging confirmation of resolution. Pain Physician 11:257-261

78. Çağlayan G, Özçakar L, Kaymak SU et al (2016) Effects of sonofeedback during aspiration of Baker's cysts: a controlled clinical trial. J Rehabil Med 48:386-389. https://doi.org/10.2340/16501 977-2049
79. Finnoff JT, Nutz DJ, Henning PT et al (2010) Accuracy of ultrasound-guided versus unguided pes anserinus bursa injections. PM R 2:732-739. https://doi.org/10.1016/j.pmrj.2010.03.014

80. Lee JH, Lee JU, Yoo SW (2019) Accuracy and efficacy of ultrasound-guided pes anserinus bursa injection. J Clin Ultrasound 47:77-82. https://doi.org/10.1002/jcu.22661

81. Lalam RK, Winn N, Cassar-Pullicino VN (2016) Interventional articular and para-articular knee procedures. Br J Radiol. doi: https://doi.org/10.1259/bjr.20150413

82. Jose J, Schallert E, Lesniak B (2011) Sonographically guided therapeutic injection for primary medial (tibial) collateral bursitis. J Ultrasound Med 30:257-261. https://doi.org/10.7863/jum.2011. 30.2.257

83. Hong JH, Kim JS (2013) Diagnosis of iliotibial band friction syndrome and ultrasound guided steroid injection. Korean J Pain 26:387-391. https://doi.org/10.3344/kjp.2013.26.4.387

Publisher's note Springer Nature remains neutral with regard to jurisdictional claims in published maps and institutional affiliations.

\section{Authors and Affiliations}

Luca Maria Sconfienza ${ }^{1,2}\left(\right.$ Miraude Adriaensen $^{3} \cdot$ Domenico Albano $^{1,4} \cdot$ Andrea Alcala-Galiano $^{5}$. Georgina Allen ${ }^{6,7}$. Maria Pilar Aparisi Gómez ${ }^{8,9}$. Giacomo Aringhieri ${ }^{10}$. Alberto Bazzocchi ${ }^{11} \cdot$ lan Beggs ${ }^{12}$. Vito Chianca ${ }^{13,14}$ - Angelo Corazza ${ }^{1}$. Danoob Dalili ${ }^{15}$. Miriam De Dea ${ }^{16}$. Jose Luis del Cura ${ }^{17}$. Francesco Di Pietto ${ }^{18}$. Elena Drakonaki ${ }^{19}$. Fernando Facal de Castro ${ }^{20}$. Dimitrios Filippiadis ${ }^{21}$. Salvatore Gitto ${ }^{2}$. Andrew J. Grainger ${ }^{22}$. Simon Greenwood ${ }^{23} \cdot$ Harun Gupta ${ }^{24}$. Amanda Isaac ${ }^{15,25}$. Slavcho Ivanoski ${ }^{26,27}$. Monica Khanna ${ }^{28}$. Andrea Klauser $^{29} \cdot$ Ramy Mansour $^{30}$. Silvia Martin ${ }^{31}$. Vasco Mascarenhas ${ }^{32,33}$. Giovanni Mauri ${ }^{34,35}$. Catherine McCarthy ${ }^{36}$. David McKean ${ }^{37}$. Eugene McNally ${ }^{36} \cdot$ Kalliopi Melaki $^{38} \cdot$ Rebeca Mirón Mombiela $^{39}$. Ricardo Moutinho ${ }^{32,40}$. Marina Obradov ${ }^{41}$. Cyprian Olchowy ${ }^{42}$. Davide Orlandi ${ }^{43} \cdot$ Raquel Prada González $^{44}$. Mahesh Prakash ${ }^{45}$. Magdalena Posadzy ${ }^{46}$. Saulius Rutkauskas ${ }^{47}$. Žiga Snoj ${ }^{48,49}$. Alberto Stefano Tagliafico ${ }^{50,51}$. Alexander Talaska ${ }^{52} \cdot$ Xavier Tomas $^{53} \cdot$ Violeta Vasilevska-Nikodinovska $^{27,54} \cdot$ Jelena Vucetic $^{55} \cdot$ David Wilson $^{6}$. Federico Zaottini ${ }^{51} \cdot$ Marcello Zappia $^{56,57}$. Carmelo Messina ${ }^{1}$

1 IRCCS Istituto Ortopedico Galeazzi, Via Riccardo Galeazzi 4, 20161 Milan, Italy

2 Dipartimento Di Scienze Biomediche Per La Salute, Università Degli Studi Di Milano, Milan, Italy

3 Department of Medical Imaging, Zuyderland Medical Center, Sittard-Geleen, Heerlen, Brunssum, Kerkrade, the Netherlands

4 Sezione Di Scienze Radiologiche, Dipartimento Di Biomedicina, Neuroscienze E Diagnostica Avanzata, Università Degli Studi Di Palermo, Palermo, Italy

5 Hospital Universitario, 12 de Octubre, Madrid, Spain

6 St Luke's Radiology Oxford Ltd, Oxford, UK

7 University of Oxford, Oxford, UK

8 Department of Radiology, Auckland City Hospital, Auckland, New Zealand

9 Department of Radiology, Hospital Vithas Nueve de Octubre, Valencia, Spain

10 Diagnostic and Interventional Radiology, Department of Translational Research and New Technologies in Medicine and Surgery, University of Pisa, Pisa, Italy
11 Diagnostic and Interventional Radiology, IRCCS Istituto Ortopedico Rizzoli, Bologna, Italy

12 Analytic Imaging, Edinburgh, UK

13 Ospedale Evangelico Betania, Napoli, Italy

14 Clinica Di Radiologia EOC IIMSI, Lugano, Switzerland

15 School of Biomedical Engineering \& Imaging Sciences, King's College London, London, UK

16 Studio MSK, Belluno, Italy

17 Hospital Universitario Donostia, San Sebastian, Spain

18 Dipartimento Di Diagnostica Per Immagini, Pineta Grande Hospital, Castel Volturno, Italy

19 MSK Radiology Services, Heraklion, Crete, Greece

20 Hospital General Universitario de Valencia, Valencia, Spain

21 2nd Department of Radiology, University General Hospital "ATTIKON" Medical School, National and Kapodistrian University of Athens, Haidari, Athens, Greece

22 Cambridge University Hospitals, Cambridge, UK

23 Mid Cheshire Hospitals NHS Foundation Trust, Cheshire, UK 
24 Leeds Teaching Hospitals, Leeds, UK

25 Guy's and St Thomas' Hospitals, London, UK

26 Department of Radiology, Special Hospital for Orthopedic Surgery and Traumatology, St. Erazmo, Ohrid, North Macedonia

27 Medical Faculty, University Ss. Cyril and Methodius in Skopje, Skopje, Macedonia

28 Imperial College Healthcare NHS Trust, London, UK

29 Department of Radiology, Medical University of Innsbruck, Innsbruck, Austria

30 Oxford Musculoskeletal Radiology, Oxford University Hospitals, Oxford, UK

31 Hospital Universitario Son Llatzer, Palma, Spain

32 Musculoskeletal Imaging Unit, Hospital da Luz, Lisbon, Portugal

33 AIRC, Advanced Imaging Research Consortium, Lisbon, Portugal

34 Division of Interventional Radiology, Istituto Europeo Di Oncologia IRCCS, Milan, Italy

35 Department of Oncology and Hemato-Oncology, University of Milano, Milan, Italy

36 Oxford Musculoskeletal Radiology, Oxford, UK

37 Buckinghamshire Healthcare NHS Trust, Aylesbury, UK

38 Department of Radiology, Charité-Universitätsmedizin Berlin, Berlin, Germany

39 Department of Radiology, Herlev og Gentofte Hospital, Herlev, Denmark

40 Hospital de Loulé, Loulé, Portugal

41 Present Address: Department of Radiology, Sint Maartenskliniek, Nijmegen, The Netherlands
42 Department of Oral Surgery, Wroclaw Medical University, Wroclaw, Poland

43 Department of Radiology, Ospedale Evangelico Internazionale, Genoa, Italy

44 Hospital POVISA, Vigo, Spain

45 Post Graduate Institute of Medical Education \& Research (PGIMER), Chandigarh, India

46 Indywidualna Praktyka Lekarska Magdalena Posadzy, Poznan, Poland

47 Department of Radiology, Lithuanian University of Health Sciences, Kaunas, Lithuania

48 Institute of Radiology, University Medical Centre Ljubljana, Zaloska 7, 1000 Ljubljana, Slovenia

49 Faculty of Medicine, University of Ljubljana, Ljubljana, Slovenia

50 Department of Health Sciences, University of Genova, Genoa, Italy

51 IRCCS Ospedale Policlinico San Martino, Genoa, Italy

52 Department of Radiology, AUVA Trauma Center, Vienna, Austria

53 Radiology Dpt. MSK Unit. Hospital Clinic (CDIC), University of Barcelona (UB), Barcelona, Spain

54 University Institute of Radiology in Skopje, Clinical Center "Mother Theresa", Skopje, Macedonia

55 Radiology Department, Hospital ICOT Ciudad de Telde, Las Palmas, Spain

56 Department of Medicine and Health Sciences, University of Molise, Campobasso, Italy

57 Varelli Institute, Naples, Italy 